\title{
Téoros
}

Revue de recherche en tourisme

\section{Le tourisme social : une réalité dynamique}

\section{Louis Jolin}

Volume 1, numéro 3, 3e trimestre 1982

Les enjeux du tourisme social

URI : https://id.erudit.org/iderudit/1080843ar

DOI : https://doi.org/10.7202/1080843ar

Aller au sommaire du numéro

Éditeur(s)

Université du Québec à Montréal

ISSN

0712-8657 (imprimé)

1923-2705 (numérique)

Découvrir la revue

Citer ce document

Jolin, L. (1982). Le tourisme social : une réalité dynamique. Téoros, 1(3), 1-1. https://doi.org/10.7202/1080843ar d'utilisation que vous pouvez consulter en ligne.

https://apropos.erudit.org/fr/usagers/politique-dutilisation/ 


\section{Le tourisme social: une réalité dynamique}

Le tourisme social recouvre l'ensemble des mesures et des programmes favorisant l'accessibilité aux vacances et au tourisme qu'ils soient de l'initiative des pouvoirs publics ou de celle des associations. Équipements d"hébergement pour les familles des travailleurs, voyages échanges pour les jeunes, campings collectifs, ces réalités se retrouvent toutes sous /'expression tourisme social dans la mesure oủ elles ont pour objectif de rejoindre les divers groupes de population quelque soient leur revenu et leurs contraintes.

Le tourisme recouvre aussi (et peut-être est-ce là l'essence du phénomène?l les diverses expériences de prise en charge par les vacanciers eux-mêmes de leurs vacances et par les communautés d'accueil, de /'organisation de services à offrir aux touristes. Le tourisme social est d'abord associatif et par le fait même se situe "en dehors du champ du profit et maintient des objectifs d'apprentissage de la responsabilité et d'éducation populaire":

Les premières expériences de tourisme social existent depuis le début du siècle tant en Europe qu'en Amérique: les colonies de vacances pour jeunes en constituent la premiere manifestation. Cependant le phénomène a connu un essor considérable en Europe dans la foulée des conquêtes des travailleurs pour les congés payés. De plus les impératifs de la reconstruction des infrastructures et du tissu social après la deuxième guerre mondiale ont favorisé l'émergence d'un secteur associatif fort, sans but lucratif, qui conjointement avec les syndicats s'est avéré le veritable moteur du développement du tourisme social (programmes, équipements, etc. I

Au Québec, le développement du tourisme social a plutôt emprunté les chemins du "loisir organisé sans but /ucratif". Au début des années 60 , dans un contexte de laïcisation rapide des institutions et de municipalisation progressive des services de loisir, le champ du loisir est investi par les pouvoirs publics et les associations volontaires de citoyens. Les uns et les autres tentent de faire contrepoids au secteur commercial en rappelant que le loisir n'est pas une simple marchandise de consommation et que le participant est plus qu'un client à satisfaire. Les associations québécoises de tourisme social s'inscrivent de plein-pied dans cette problematique. ${ }^{2}$

$$
\text { .. }
$$

I/ y a une vingtaine d'années naissait le Bureau international de tourisme social qui regroupe maintenant une centaine d'organismes nationaux et internationaux et p/usieurs gouvernements à majorité européens. Quelques associations québécoises y sont représentées mais aucune association du Canada anglais et des Etats-Unis n'est présente au B.I.T.S. actuellement. Le tourisme social peut-il être américain? Très certainementl Au delà des discussions de sémantique (parle-t-on aux Etats-Unis de tourisme social, de tourisme populaire?), même si le concept lui-meme est peu répandu, p/usieurs réalisations canadiennes et américaines procèdent du phénomène de tourisme social. Cependant le discours idéologique est peut-ètre différent du discours européen, les réalisations revêtent certes des caractéristiques spécifiques au contexte nord-américain.

Après avoir tenu son Congrès en 1980 au Québec, le B.I.T.S. a décidé d'organiser, via sa commission pour I"Amérique du Nord, une importante conférence nordaméricaine sur le tourisme social et associatif dont les objectifs sont justement de réunir le plus grand nombre d'intervenants nord-américains préoccupés par la dimension sociale du tourisme, de permettre le maximum d'échanges sur les expériences et projets réalisés un peu partout aux États-Unis, au Canada et au Québec, d'analyser et confronter le concept de tourisme social en relation avec les réalités nord-américaines.

Cette conférence a lieu du 3 au 5 novembre 1982 à I'Université du Québec à Montréal. Le module de gestion et intervention touristiques s'est associé avec enthousiasme à la réalisation de cette conférence. Le présent numéro de Téoros veut souligner cet important courant du phénomène touristique en regroupant quelques textes qui cernent certains aspects de la réalité québécoise du tourisme social et soulèvent des enjeux pour la décennie 80 .

Le tourisme social, est-jl nécessaire de le rappeler, ne représente pas qu'un secteur d'activités aussi important soit-il. Au contrairel Les associations de tourisme social interpe/lent l'ensemble du monde du tourisme qui a trop souvent tendance à ne considérer que les dimensions économiques du phénomène. Les intervenants en tourisme social rejettent cette perspective et proposent en retour une politique sociale qui, basée sur les dimensions sociales et culturelles du tourisme, permet la valorisation du tourisme comme moyen d'épanouissement individuel et collectif sans pour autant minimiser les incidences économiques ultérieures.

Louis Jolin

1II R. LAFDUAR at Y. AAYWOUARD, Le tourisme social, Paris, P.U.F, collection Que sas je, 1978 p. 9

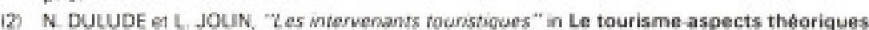
at pratiques au Quabes, Montrial, Sodilis, 1992, p. 201. 